\title{
PERANCANGAN APLIKASI HOSTELRY DENGAN TEKNOLOGI LOCATION BASED SERVICE BERBASIS ANDROID UNTUK MENDUKUNG SEKTOR PARIWISATA DI BULUKUMBA
}

\author{
Nuraida Latif ${ }^{1}$, Rohayati Arifin ${ }^{2}$, Andi Diaunnajiyah ${ }^{3}$ \\ ${ }^{1}$ Teknik Informatika STMIK AKBA Makassar \\ ${ }^{2,3}$ Sistem Informasi STMIK AKBA Makassar \\ 1nuraida@akba.ac.id , $\underline{\text { rohayati@akba.ac.id }}$
}

\begin{abstract}
ABSTRAK
Penelitian ini bertujuan untuk Merancang aplikasi Hostelry dengan Teknologi Location Based Service (LBS) berbasis android untuk pendukung sektor pariwisata di Bulukumba, Mengimplementasikan aplikasi Hostelry berbasis android di Kabupaten Bulukumba. Data data diperoleh melalui penelitian lapangan berupa wawancara, dokumentasi dan penelitian pustaka. Jumlah sampel yang diambil dalam penelitian ini terbagi menjadi 3 kategori yaitu penginapan, wisata, dan pasar. Perhitungan pengambilan sampel dari populasi menggunakan rumus Slovin dengan jumlah sampel data 48 penginapan dari 93 data penginapan, 23 wisata dari 30 data wisata, dan 30 pasar dari 42 data pasar. Pengujian aplikasi menggunakan metode pengujian blackbox dan User Acceptance Testing (UAT). Hasil penelitian menunjukkan bahwa aplikasi Hostelry Bulukumba dapat memudahkan wisatawan dalam memilih dan melakukan pencarian lokasi penginapan dengan tingkat kelayakan rata-rata 95,2\% dari 22 responden.
\end{abstract}

Kata Kunci : Location Based Service, Android, Pariwisata, Penginapan, Bulukumba

\begin{abstract}
The aims of the study were to design the Hosterly application with Android LBS technology in supporting tourism sector in Bulukumba and to implement the application with Android used in Bulukumba Regency. The data was obtained through Field Research, in the form of interview and documentation, and Library Research.This application was provided with php, java, and MySQL programming language to manage the database. The sample was devided into 3 categories:namely hostelry, tour, and market. The calculation of collecting population sample used Slovin formula with the number of data are 48 of 93 hostelries, 23 of 30 tours, and 30 of 42 markets. Its application was tested through Blackbox and User Acceptance Testing (UAT) methods. The result of the study indicated that the Hostelry application for Bulukumba facilitated the tourists to choose and search the location of Hostelry with the average of feasibility $95,2 \%$ of 22 respondents.
\end{abstract}

Keywords : Location Based Service, Android, Tourism, Lodging, Bulukumba. 


\section{PENDAHULUAN}

Pariwisata merupakan salah satu sektor yang diandalkan pemerintah untuk memperoleh devisa dari penghasilan non migas. Peran pariwisata dalam pembangunan nasional, disamping sebagai sumber perolehan devisa juga banyak memberikan sumbangan terhadap bidang-bidang lain, diantaranya menciptakan dan memperluas lapangan usaha, meningkatkan pendapatan masyarakat, mendorong pelestarian lingkungan hidup dan budaya bangsa, memperkokoh persatuan dan kesatuan bangsa.

Bulukumba sebagai salah satu Kabupaten di Provinsi Sulawesi Selatan yang berada pada kondisi empat dimensi, yakni dataran tinggi pada kaki Gunung Bawakaraeng - Lompobattang, dataran rendah, pantai dan laut lepas. Kabupaten Bulukumba terletak di ujung bagian selatan ibu kota Provinsi Sulawesi Selatan, terkenal dengan industri perahu phinisi yang banyak memberikan nilai tambah ekonomi bagi masyarakat dan Pemerintah Daerah. Kabupaten Bulukumba merupakan salah satu pusat pengembangan pariwisata bagian selatan Provinsi Sulawesi Selatan. Pembangunan kepariwisataan di Kabupaten Bulukumba mempunyai peluang untuk dikembangan yaitu wisata alam bahari, budaya, sejarah dan agrowisata. Bulukumba mempunyai kekayaan alam yang beraneka ragam dengan ciri khas berbeda dengan daerah lain. Potensi wisata ini perlu dikembangkan karena merupakan modal besar untuk menarik pengunjung agar berkunjung ke Bulukumba.

Namun masalah yang dihadapi oleh wisatawan yaitu mereka kesulitan dalam menentukan penginapan yang sesuai dengan harapan. Wisatawan juga kesulitan mencari penginapan yang berada di sekitar wisata dan petunjuk arah menuju lokasi penginapan. Pada umumnya, wisatawan mengutamakan pencarian penginapan berdasarkan jarak dari tempat wisata dan fasilitas penginapan. Sebagai solusi dari permasalahan diatas, maka diusulkan untuk dikembangkan suatu aplikasi hostelry berbasis android yang dapat membantu wisatawan dalam negeri maupun luar negeri dalam melakukan pencarian tempat penginapan. Oleh karena itu penulis tertarik untuk merancang laporan penelitian ini dengan judul "Perancangan Aplikasi Hostelry Dengan Teknologi Location Based Service Berbasis Android Untuk Mendukung Sektor Pariwisata Di Bulukumba".

\section{LANDASAN TEORI}

\subsection{Android}

Menurut Yudhanto dan Wijayanto (2018:1) Android adalah sistem operasi berbasis Linux yang dirancang untuk perangkat bergerak layar sentuh seperti telepon

pintar dan komputer tablet. Android awalnya dikembangkan oleh Android, Inc., dengan dukungan finansial dari Google, yang kemudian membelinya pada tahun 2005. Sistem operasi ini diriis secara resmi pada tahun 2007, bersamaan dengan didirikan Open Handset Alliance, konsorsium dari 34 perusahaan hardware, software, dan telekomunikasi, termasuk Google, HTC, Intel, Motorola, Qualcomm, T-Mobile, Nvidia, dan lain-lain.

\subsection{Location Based Service (LBS)}

Location Based Service (LBS) adalah layanan informasi yang dapat diakses menggunakan piranti mobile melalui jaringan internet dan seluler serta memanfaatkan kemampuan penunjuk lokasi pada mobile. LBS juga diartikan sebuah layanan $I P$ - nirkabel yang menggunakan informasi geografi untuk memberikan layanan kepada pengguna perangkat mobile. Setiap layanan aplikasi yang memanfaatkan posisi terminal mobile. Location Based Service (LBS) adalah sebuah nama umum untuk layanan baru dimana informasi lokasi menjadi parameter utama.

\subsection{Global Position System (GPS)}

Global Positioning System (GPS) adalah suatu sistem navigasi menggunakan lebih dari 24 satelit MEO (Medium Earth Orbit atau Middle Earth Orbit) yang mengelilingi bumi sehingga penerima-penerima sinyal di permukaan bumi dapat menangkap sinyalnya. GPS mengirimkan sinyal gelombang mikro ke Bumi. Sinyal ini diterima oleh alat penerima di permukaan, dan digunakan untuk menentukan letak, kecepatan, arah, dan waktu. Satelit mengorbit pada ketinggian 12.000 mil diatas bui dan mampu mengelilingi bumi dua kali dalam 24 jam. Satelit GPS secara kontinyu mengirimkan sinyal radio digital yang mengandung data lokasi satelit dan waktu, pada peneima yang berhubungan. Satelit GPS dilengkapi dengan jam atom yang mempunyai ketetapan waktu satu per sau juta detik. Berdasarkan informasi ini, stasiun penerima mengetahui berapa lama waktu yang digunakan untuk mengirim sinyal sampai kepada penerima di bumi.

\subsection{Google Maps API}

Google Maps API merupakan pengembangan teknologi dari Google yang digunakan untuk menanamkan Google Map di suatu aplikasi yang tidak dibuat oleh Google. Google Maps API adalah suatu library yang berbentuk javascript yang berguna untuk memodifikasi peta yang ada di Google Maps sesuai kebutuhan. Dalam perkembangannya Google Maps API diberikan kemampuan untuk mengambil gambar peta statis. Melakukan 
geocoding, dan memberikan penuntun arah. Google Maps API bersifat gratis untuk publik.

\subsection{Aplikasi Hostelry}

Aplikasi Hostelry Bulukumba adalah sebuah aplikasi yang dapat membantu wisatawan nusantara maupun mancanegara dalam melakukan pencarian penginapan, wisata dan pasar. Aplikasi ini juga membantu wisatawan dalam memilih penginapan yang dekat dengan lokasi wisatawan, serta membantu wisatawan menemukan rute menuju lokasi. Aplikasi ini hanya bisa digunakan pada platform android, dan dibuat client server. Jadi informasi yang terdapat pada aplikasi dapat diperbaharui dari sebuah webserver

\section{METODOLOGI}

\subsection{Teknik Pengumpulan Data}

Teknik Pengumpulan data yang digunakan adalah sebagai berikut :

a. Studi Pustaka

- Pada tahap ini dilakukan pengumpulan data dan informasi dengan mencari, membaca, mencatat inti sari dan mempelajari buku-buku, referensireverensi, jurnal yang relevan, situs-situs internet serta tinjauan pustaka yang berkenaan dengan topic yang akan dijadikan acuan pembahasan dalam penelitian ini

b. Studi Lapangan

Penelitian lapangan dilakukan dengan mengumpulkan dan menelaah informasi mengenai data-data parawisata yang ada di Bulukumba

\subsection{Perancangan Use Case}

Use case diagram admin pada Gambar 1 menjelaskan bahwa admin berperan sebagai aktor. Admin dapat mengelolah data penginapan, data wisata, dan data pasar, serta melihat informasi peta lokasi. Tetapi, sebelum admin melakukan tugas tersebut ada include yang mengharuskan admin untuk login kedalam sistem.

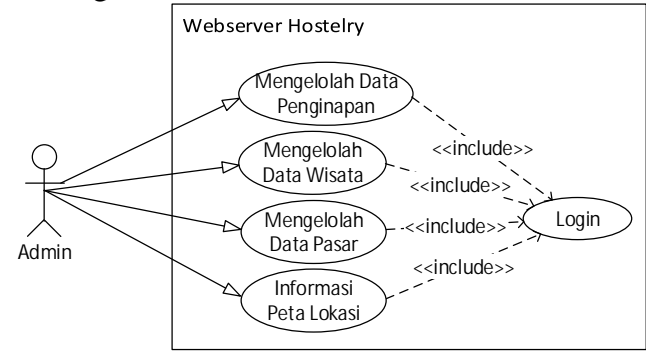

Gambar 1. Use Case Diagram Admin

Use case diagram wisatawan pada Gambar 2 menjelaskan bahwa wisatawan berperan sebagai aktor. Wisatawan dapat melihat informasi penginapan, informasi wisata, informasi pasar, informasi peta Bulukumba dan melihat rute menuju lokasi.

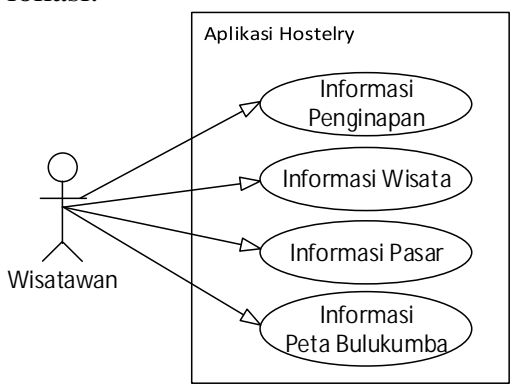

Gambar 2. Use Case Diagram Wisatawan

\section{HASIL DAN PEMBAHASAN}

\subsection{Hasil}

Halaman login pada gambar 3 merupakan form yang tampil pertama kali untuk masuk ke dalam sistem, login ini digunakan demi keamanan agar tidak semua dapat mengakses menu admin.

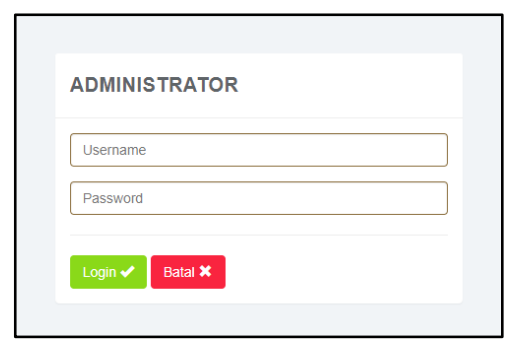

Gambar 3. Halaman Login Admin

Halaman dashboard pada gambar 4 merupakan tampilan awal yang muncuk ketika login berhasil. Pada halaman ini terdapat beberapa menu untuk mengelolah data.

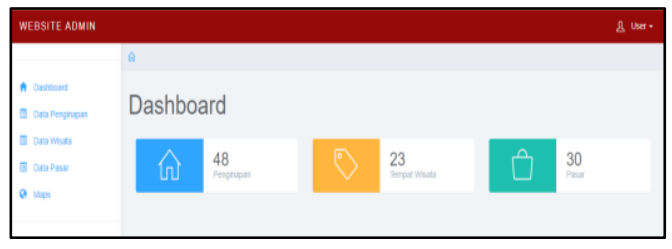

Gambar 4. Dashboard Admin

Halaman data penginapan pada gambar 5 berisi data-data penginapan yang telah diinput berupa nama penginapan, alamat, fasilitas, harga sewa, keterangan, koordinat latitude, koordinat longitude, serta foto penginapan. Pada halaman ini, admin bisa menambahkan, mengedit dan menghapus data penginapan. 


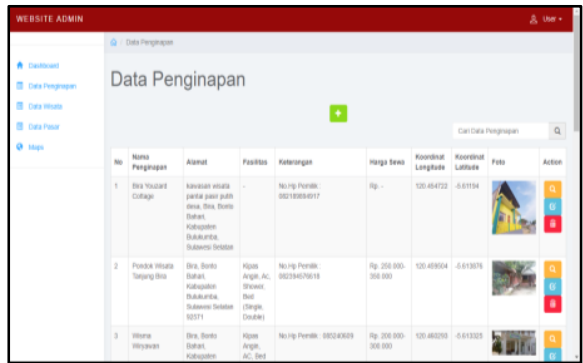

Gambar 5. Halaman Data Penginapan

Halaman data wisata pada gambar 6 berisi data-data wisata yang telah diinput berupa nama wisata, alamat, keterangan, koordinat latitude, koordinat longitude, serta foto tempat wisata. Pada halaman ini, admin juga bisa menambahkan, mengedit dan menghapus data wisata.

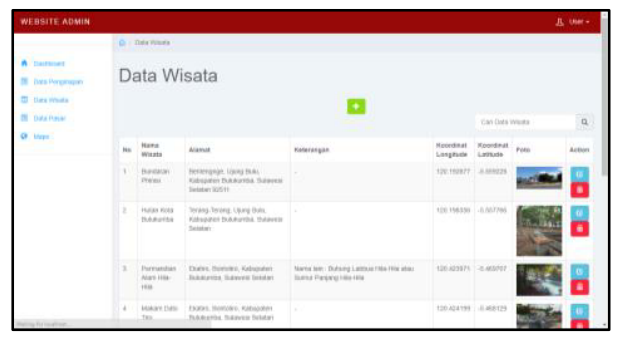

Gambar 6. Halaman Data Wisata

Halaman data pasar pada gambar 7 berisi data-data pasar yang telah diinput berupa nama pasar, alamat, keterangan, koordinat latitude, koordinat longitude pasar serta foto pasar. Pada halaman ini, admin juga bisa menambahkan, mengedit dan menghapus data pasar.

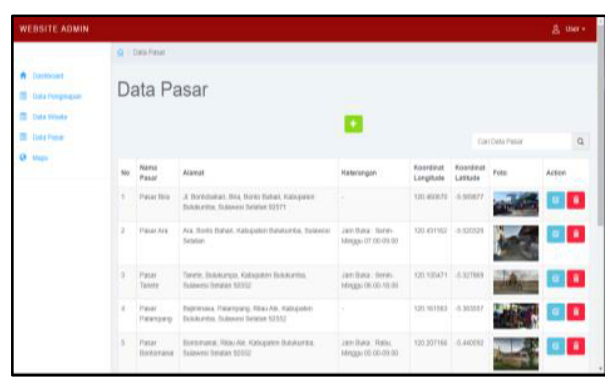

Gambar 7. Halaman Data Pasar

Halaman peta bulukumba pada gambar 8 , admin dapat melihat titik lokasi dari penginapan, tempat wisata dan pasar yang telah diinput sebelumnya.

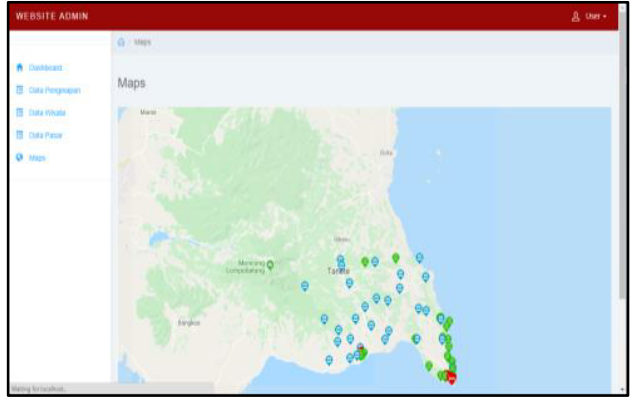

Gambar 8. Peta Bulukumba

Pada saat membuka aplikasi, halaman splash screen akan muncul seperti pada gambar 9 sebagai tampilan awal aplikasi sebelum masuk ke halaman utama aplikasi.

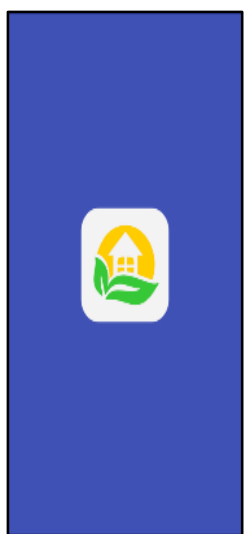

Gambar 9. Halaman Splash Screen Aplikasi

Setelah halaman splash screen muncul, maka halaman utama akan tampil seperti pada gambar 10. Halaman utama ini berisi beberapa menu yang dapat diakses oleh pengguna yaitu daftar penginapan, daftar wisata, daftar pasar, peta bulukumba, dan tentang aplikasi.

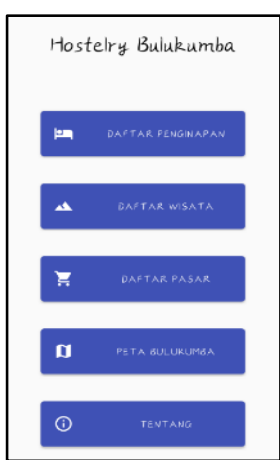

Gambar 10. Halaman Utama Aplikasi

Halaman daftar penginapan pada gambar 11 berisi nama-nama penginapan yang ada di kabupaten Bulukumba beserta alamat dan harga sewa penginapan. Halaman ini juga terdapat pencarian untuk memudahkan 
pengguna mencari penginapan yang diinginkan.

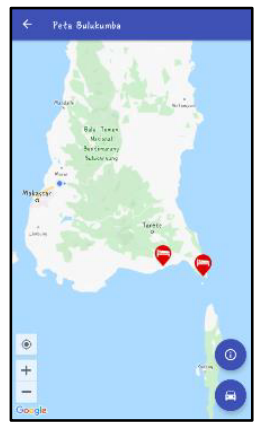

Gambar 11. Halaman Daftar Penginapan

Halaman daftar wisata pada gambar 12 berisi nama-nama tempat wisata yang ada di kabupaten Bulukumba beserta alamat tempat wisata. Pada halaman ini pengguna juga bisa melakukan pencarian nama tempat wisata yang ingin dikunjingi.

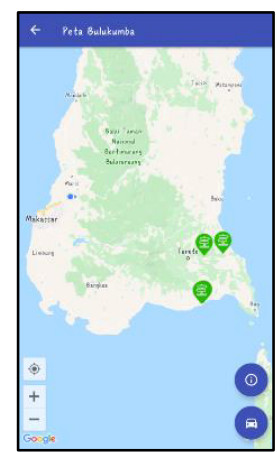

Gambar 12. Halaman Daftar Wisata

Halaman daftar pasar pada gambar 13 berisi nama-nama pasar yang ada di kabupaten Bulukumba beserta alamat pasar. Pada halaman ini pengguna juga bisa melakukan pencarian pasar yang ingin di kunjungi.

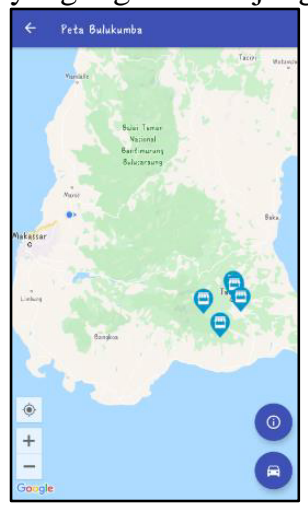

Gambar 13. Halaman Daftar Pasar

Pada halaman ini ditampilkan peta lokasi kabupaten bulukumba beserta titik lokasi penginapan, wisata, dan pasar. Icon berwarna merah menandakan lokasi penginapan, icon berwarna hijau menandakan lokasi wisata, dan icon berwarna biru menandakan lokasi pasar seperti pada gambar 14 .

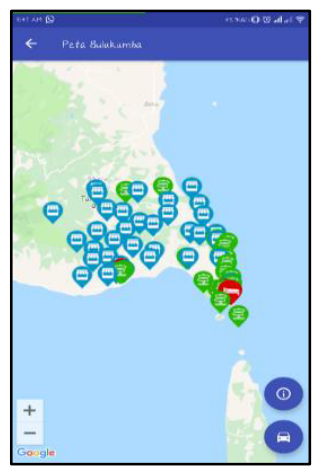

Gambar 14. Halaman Peta Bulukumba

\subsection{Pembahasan}

Pengujian menggunakan teknik UAT

(User Acceptance Testing) yaitu suatu proses pengujian yang dilakukan oleh pengguna dengan hasil output sebuah dokumen hasil uji yang dapat dijadikan bukti bahwa software sudah diterima dan sudah memenuhi kebutuhan yang diminta. Untuk mengetahui tahapan responden (user) terhadap aplikasi izin kelayakan, maka dilakukan pengujian dengan memberikan 9 pertanyaan.

Setelah melakukan perhitungan dengan menggunakan pengujian UAT, dapat disimpulkan bahwa aplikasi Hostelry Bulukumba mempunyai tampilan yang user friendly, aplikasi dapat berjalan dengan baik di smartphone android, menu-menu pada aplikasi mudah dipahami, informasi yang disediakan mudah dimengerti, adanya melihat lokasi dan petunjuk arah membantu dalam menemukan lokasi objek serta sistem sangat dibutuhkan sehingga dikatakan layak dengan rata-rata $95.2 \%$.

\section{KESIMPULAN}

Dari hasil perancangan dan implementasi aplikasi Hostelry Bulukumba disimpulkan bahwa aplikasi ini dirancang menggunakan teknologi location based service (LBS) untuk pengambilan koordinat latitude, longitude, menentukan lokasi awal dan tujuan, serta menghitung arah dan jarak alternatif dari lokasi user menuju lokasi tujuan.

Pengimplementasian aplikasi ini sudah sesuai dengan fitur dan fungsinya yang diharapkan sehingga dapat menjadi alternatif bagi wisatawan dalam memilih dan melakukan pencarian lokasi penginapan, tempat wisata, dan pasar yang akan di kunjungi. Hasil pengujian user acceptance test (UAT) terhadap aplikasi ini telah dikatakan layak dengan tingkat kelayakan rata-rata 95.2\%. 
Universitas AL Asyariah Mandar

\section{DAFTAR PUSTAKA}

[1] Artikel Ilmiah. 2015. Perancangan dan Implementasi Location Based Sevice Pada Sistem Informasi Geografis Pariwisata Kabupaten Sumba Barat Daya. Salatiga: Fakultas Teknologi Informasi Universitas Kristen Satya Wacana.

[2] Ariyanti, Rena, Khairil, dan Indra Kanedi. 2015. Pemanfaatan Google Maps API Pada Sistem Informasi Geografis Direktori Perguruan Tinggi Di Kota Bengkulu. Bengkulu : Jurnal Media Infotama.

[3] Dinas Pariwisata Bulukumba. 2018. Profil Dinas Pariwisata Kab. Bulukumba 2018.

[4] Iwan Nasrulloh. 2017. Rancang Bangun Aplikasi Location Based Service Wisata Populer di Jawa Timur Berbasis Android Dengan Metode Extreme Programming. Yogyakarta: Fakultas Sains dan Teknologi UIN Sunan Kalijaga.

[5] Maghribi, Charisma Audia, Aliyadi, dan Ghulam Asrofi. 2017. Rancang Bangun Pembuatan Aplikasi TIC (Tourist Information Center) Ponorogo Berbasis Android Menggunakan SIG dan Web Server. Ponorogo: Penerbitan Artikel Mahasiswa Universitas Muhammadiyah Ponorogo.

[6] Nugroho, Widi Novian. 2017. Aplikasi Pencarian Masjid Terdekat Di Kota Bandar Lampung Berbasis Mobile Menggunakan Algoritma Dijkstra. Bandar Lampung: Fakultas Matematika dan Ilmu Pengetahuan Alam Universitas Lampung.

[7] Supriadi, Bambang dan Nanny Roedjinandari. 2017. Perencanaan dan Pengembangan Destinasi Pariwisata. Malang : Universitas Negeri Malang.

[8] Yudhanto, Yudha, dan Ardhi Wijayanto. 2018. Mudah Membuat dan Berbisnis Aplikasi Android dengan Android Studio. Jakarta: Elex Media Komputindo. 